\title{
SPECTRUM OF COMPLAINTS PRESENTED AT A SPECIALIST BREAST CLINIC IN KUMASI, GHANA
}

\author{
M. OHENE-YEBOAH and E. P. AMANING \\ Department of Surgery, School of Medical Sciences, Kwame Nkrumah University of Science and Technology, \\ University Post Office, Kumasi, Ghana
}

\author{
Author for correspondence: Dr Michael Ohene-Yeboah E-Mail: mikeoheneyeboah@yahoo.co.uk \\ Conflict of Interest: None declared
}

\section{SUMMARY}

Background: In Ghana data on breast disease is lacking. Objective: To describe the type of complaints presented at a specialist clinic.

Study Design: A prospective descriptive study.

Setting: The Komfo Anokye Teaching Hospital Breast Care Centre (KATH-BCC)

Method: Data including the age, type of complaints, the clinical, radiological and histological diagnosis was obtained and recorded from all consecutive adult patients seen and treated at the KATH-BCC between July 2004 and March 2005.

Results: A total of 1678 patients were studied. There were 10 males. The ages of the patients varied between one month and 95 years. The three most common complaints were breast pain $1210(72.1 \%)$, breast lump 312 (18.6\%), nipple discharge $96(5.7 \%)$ and other miscellaneous condition $60(3.6 \%)$. The three most common finding in the 1210 patients with breast pain were normal breast $736(60.8 \%)$, fibrocystic breast changes 200 $(16.5 \%)$ and breast abscess or mastitis $161(13.3 \%)$. The main histological types of the 312 breast lumps were fibroadenomata $159(51.0 \%)$, fibrocystic changes 97 (31.1\%) and carcinoma 56 (17.9\%).

Conclusion: Breast pain is the most common breast related problem presented at our specialist breast clinic. One in five women with a breast lump had cancer.

Keywords: Breast complaints, Breast pain, Breast cancer, Breast disease patterns, Ghana

\section{INTRODUCTION}

Due to the considerable morbidity and mortality from communicable diseases and malnutrition, many countries in Africa have no well-defined breast care services. ${ }^{1}$ In Ghana most patients with breast related problems are seen at a general out-patient or at a general surgical clinic. The effect of this arrangement is often the late diagnosis of breast diseases and breast cancer in our population.

It is generally accepted that the introduction of specialist breast clinics alongside breast cancer screening pro- grammes has contributed to the early diagnosis and treatment of breast cancer in the developed countries with more resources for health care. ${ }^{2}$ In our hospital it has been observed that a large number of breast cancer cases have serious inadequacies in breast care. It is against this background that a specialist clinic was setup to provide the early diagnosis and systematic standardized approach to the management of women with breast problems and breast cancer.

The Komfo Anokye Teaching Hospital Breast Care Centre (KATH-BCC) was established in July 2004 to cater for all patients with breast complaints. It is to serve the community by an open attendance method that requires no referrals. It has two (6-hour) clinic days per week, two surgical specialists, one nurse and one health aid. It has an autonomous Medical Records and a revenue collector. This paper presents the preliminary results of our efforts to provide dedicated specialist breast care service to the women in metropolitan Kumasi.

\section{METHOD}

Between July 12004 and March 312005 all patients seen at the BCC were evaluated by a clinical history including a detailed history of the breast compliant presented, a physical examination and a clinical breast examination (CBE). As required ultrasonography, mammography, Fine Needle Aspiration (FNAC) and excision biopsy were used to assess all breast masses. The diagnosis of fibroadenosis or fibrocystic breast changes was partly clinical - painful, tender lumpy breasts - and partly by the histology of excised breast lumps. A clinical breast examination was reported as normal when no abnormal findings were noted after the palpation of the breasts, the axilla, and the supra and infra clavicular fossae. Treatment was offered according to the diagnosis made. Follow up was arranged for between 1 month and 3 months. At discharge from the clinic, a final diagnosis either clinical, FNAC or histology was made.

\section{RESULTS}

One thousand six hundred and seventy eight patients were seen and treated at the KATH-BCC. There were 10 
males. The three most common complaints were breast pain $1210(72.1 \%)$, breast lump $312(18.6 \%)$, nipple discharge $96(5.7 \%)$ and other miscellaneous conditions 60 $(3.6 \%)$. The ages of the patients varied from one month to 95 years. The peak age of incidence for breast pain was 40- 49 years, 478 patients $(28.5 \%)$. The peak age of incidence for breast lump was $20-29$ years, 133 patients $(42.0 \%)$.

Table 1 Duration of symptoms

\begin{tabular}{|l|l|l|}
\hline Symptoms & $\begin{array}{l}\text { Time Interval } \\
\text { (Days) }\end{array}$ & $\begin{array}{l}\text { Median } \\
\text { (Days) }\end{array}$ \\
\hline Breast Pain & $2-30$ & 21 \\
\hline Breast Lump & $30-180$ & 90 \\
\hline Nipple Discharge & $5-15$ & 7 \\
\hline
\end{tabular}

The duration of symptoms before presentation varied between 2 days to 3 years. The mean time interval between onset of symptoms and presentation at the clinic was 3 weeks, 3 months and 1 week for breast pain, breast lump and (bloody) nipple discharge respectively (Table 1). The reasons for the delay in presentation for breast lumps were painless in $234(75 \%)$, might disappear with time in $47(15 \%)$ and waiting to see $31(10 \%)$, of the patients.

Table 2 Final diagnosis in 1550 patients

\begin{tabular}{l|l|l}
\hline Diagnosis & Number & Percent \\
\hline Normal & 736 & 47.5 \\
Cancer & 56 & 3.6 \\
Fibroadenosis & 297 & 19.2 \\
Fibroadenoma & 159 & 10.3 \\
Abscess & 161 & $10 . .4$ \\
Duct Pappilloma & 81 & 5.2 \\
Others & 60 & 3.9 (see \\
Total & 1550 & Table 3) \\
\hline
\end{tabular}

The three most common findings in the 1210 patients with breast pain were normal breast $736(60.8 \%)$, fibroadenosis $200(16.5 \%)$ and breast abscess or mastitis $161(13.3 \%)$. The main histology of the 312 breast lumps were fibroadenomas $159(51.0 \%)$, fibrocystic breast changes or fibroadenosis $97(31.1 \%)$ and carcinoma 56 $(17.9 \%)$. The rest of the results are shown in Tables 2 and 3.

\section{DISCUSSION}

Majority of women seen at the KATH-BCC were young and complained mostly of breast pain. Previous studies from general surgical clinics and specialist breast centers have reported similar results. ${ }^{3-6}$ Breast pain causes considerable morbidity and anxiety world-wide. ${ }^{6-7}$ The results of various clinical trials in Europe, America and Asia have provided some data to guide clinicians treating women with breast pain.,11 In our hospital treatment schedules based on data from our African populations are yet to be developed.

Table 3 Miscellaneous Diagnoses

\begin{tabular}{ll} 
Diagnosis & $\begin{array}{l}\text { No. of } \\
\text { Patients }\end{array}$ \\
\hline Gynaecomastia & 10 \\
Mastitis of puberty & 5 \\
Painful Scar & 5 \\
Burular skin & 1 \\
Mondor's disease & 1 \\
Hyperplasia & 5 \\
Hypoplasia & 3 \\
Hypertrophy & 3 \\
Breast cyst & 7 \\
Skin Conditions & 3 \\
Galactocoele & 4 \\
Sebaceous cyst & 5 \\
Lipoma & 2 \\
Heamangioma & 2 \\
Foreign body (Bullet) & 1 \\
Duct ectasia & 1 \\
Total & 60 \\
\hline
\end{tabular}

Previous studies that have investigated the relation between breast cancer and breast pain from various populations have reported variable results. Duigin and coworkers reported that cancer was detected in only $0.4 \%$ of patients having mammography for breast pain with no other syptmom..$^{12}$ Mansel in a review of breast pain stated that only $7 \%$ of patients with breast cancer have mastalgia as the only symptom ${ }^{13}$ Preece et al found that $15 \%$ of patients with operable cancer had pain as one of the presenting symptoms. ${ }^{14}$ A study on mastalgia and breast tumour in Nigerian women reported that $8.3 \%$ of patients with histologically proven malignant breast tumour had pain in addition to the breast lump. ${ }^{15}$

In this series no cancer was detected after a combination of CBE, ultrasonography in a large number of women presenting with breast pain only. The incidence of operable breast cancer in women presenting with breast lumps in this series was $17.5 \%$. This figure compares favourably with the reported range of $15-25 \%{ }^{3,5,16}$ The delay in presentation of breast lumps as compared with breast pain reported in this series suggests that we need to educate our population on the risk factors in breast cancer. 
The results of this study suggest that many women consider painless breast lumps as harmless. Large scale health education programmes aimed at effectively informing the public on the breast cancer risks are needed.

The spectrum of breast problems in our series is similar to that reported in other series ${ }^{3-5,16}$ The relative proportion of benign disease however may vary from populations. ${ }^{5,16}$ In this series the large number of patients with benign problems could overwhelm the few facilities and trained clinicians dealing with breast cancer. Other countries with limited health care resources like Ghana have achieved good results with the widespread use of clinical breast examination (CBE) as a means to triage or screen patients with breast symptoms. ${ }^{17}$ This provides for the management of patients with benign breast problems at a lower level facility level using trained general physicians and midwives. ${ }^{17}$

\section{CONCLUSION}

Breast pain is the most common complaint in patients reporting at our specialist breast clinic. Nearly one out of every five women seen at the clinic with a breast lump had cancer. However the breast lump was less often reported. Health education is needed to increase public awareness of breast lumps as a risk factor for breast cancer.

\section{ACKNOWLEDGEMENT}

The authors are grateful to the entire KATH-BCC staff for their role in the preparation of this manuscript.

\section{REFERENCES}

1. 1. World Health Organization. Executive Summary. In: National Cancer Control Programmes. Policies and Managerial Conferences - Geneva Switzerland. WHO 2002 ii - xxiv

2. Jennal A, Thomas A, Murray T, Thun N. Cancer statistics 2002. CA Cancer J. Chn.2002;52: 23-47

3. Cox Pj, Li MKW, Ellis H. Spectrum of breast disease in out-patient surgical practice. J. Roy. Soc. Med. 1982; ; 75: 857 - 859

4. Khanna R, Khanna S, Chaturvedi S, Arya NC. Spectrum of breast disease in young females: a retrospec- tive study of 1315 patients. Indian J. Pathol. Microbiol 1998;41: 397-401

5. Ihekwaba F.N. Benign breast disease in Nigerian women: a study of 657 patients J.R. Coll. Surg. Edin 1994; 39:280-283.

6. Leinster SJ, Whitehouse GH, Walsh PV. Mammography observations in a screened population. $B r . J$. Surg. 1987; 74: $200-2$

7. Prance SE, Pass HA. Etiology and management of breast pain IN: Singletary SE, Robb GL, Hortobagy GN, editors. Advance Therapy of breast disease. $2^{\text {nd }}$ Edition. London. BC Becker. 2004. Pg 25 - 36

8. Mansel RE, Preece PE, Hughes LE A double blind trial of the prolactin inhibitor Bromocriptine in painful benign breast disease Br. J. Surg. 1978; 65: 724727

9. Cheung KL. Management of cyclical mastalgia in Oriental women: pioneer Experience of using gamolenic acid (Efamast) in Asia. Aust. N. Z.J. Surg 1999;69:492-4

10. Pashbly NL, Mansel RE, Hughes LE, Handship J, Preece PE. A clinical trail of Evening primrose oil in mastalgia. Br. J. Surg. 1981; 68:801-824.

11. Blue J, Harman J. Mastalgia review: St. Marks Breast Centre. NZ Med J. 1998; 111;33-34

12. Duijm LE, Guit GL, Hendriks JH, et al. Value of breast imaging in women with Painful breasts: observational follow up study. $\mathrm{Br}$ Med $J .1998 ; 317$ : 1492-1495.

13. Mansel RE. The ABC of breast disease; Breast Pain. BMJ. 1994; 309: 866-868.

14. Preece PE, Baum M, Mansel RE et al. Importance of mastalgia in operable breast Cancer. BMJ. 1982; 284: 1299-1300.

15. Chiedozie LC, Guirguis MN. Mastalgia and breast tumour in Nigerian women. West Afr. J. Med 1990; 9: $54-58$

16. Asuuman R, Vowotor R, Naaeder SB. Pattern of Breast Disease in Ghana. Ghana Med J 2000; 34:206 $-210$

17. Zotov V, Shyynan R. Introduction of Breast Cancer Screening in Chernihiv Oblast in the Ukraine: Report of a PATH Breast Cancer Assistance Program Experience 